\title{
antie \\ Looking Back to Move Forward: A Bibliometric Analysis of Consumer Privacy Research
}

\author{
Sheng Shu* and Yi Liu
}

check for updates

Citation: Shu, S.; Liu, Y. Looking

Back to Move Forward: A

Bibliometric Analysis of Consumer Privacy Research. J. Theor. Appl.

Electron. Commer. Res. 2021, 16,

727-747. https://doi.org/10.3390/ jtaer16040042

Received: 30 October 2020

Accepted: 11 January 2021

Published: 14 January 2021

Publisher's Note: MDPI stays neutral with regard to jurisdictional clai$\mathrm{ms}$ in published maps and institutional affiliations.

Copyright: $(\odot 2021$ by the authors. Licensee MDPI, Basel, Switzerland. This article is an open access article distributed under the terms and conditions of the Creative Commons Attribution (CC BY) license (https:// creativecommons.org/licenses/by/ $4.0 /)$.
Antai College of Economics and Management, Shanghai Jiao Tong University, Shanghai 200240, China; liuyi76@sjtu.edu.cn

* Correspondence: nateshu2016@sjtu.edu.cn

\begin{abstract}
Information privacy has attracted considerable attention in the information system research field. However, little effort has been made to review its latest developments from a marketing perspective. As research on consumer privacy advances rapidly, a comprehensive evaluation of the field is required. In this paper, two bibliographic databases retrieved from Web of Science were used to perform a series of bibliometric analyses consisting of co-citation analysis, co-occurring keyword analysis, and structural variation analysis. To facilitate these analyses, we use the software CiteSpace. Our results present the existing literature's publication performance, thematic concentration, intellectual turning points and influential studies, and identify emerging trends in the literature. We found that a number of landmark studies has greatly affected the development of the consumer privacy research. Most importantly, this study proposes a research agenda for the field. Recent emerging topics focusing on privacy calculus, privacy ethic, privacy enhancing technologies, privacy-related coping strategies, and new contemporary privacy contexts should be further discussed in the future research.
\end{abstract}

Keywords: consumer privacy; bibliometric analysis; literature review; citespace; emerging trend

\section{Introduction}

In recent decades, numerous commercial and information techniques have emerged that aim to help firms obtain access to consumers' information data more easily [1,2]. Such unprecedented technological innovation has brought consumers greater convenience while confronting them with privacy data vulnerability and unfair information practices [3-8]. A plethora of scholars and policy makers have sought legal, commercial, and technological solutions to protect consumers from privacy violations, but the misuse and abuse of information continue to emerge.

Against this backdrop, marketing scholars have contributed various ideas and investigations. For example, in the 1990s, there were many notable academic contributors, such as Goodwin [9], Jones [10], Smith, Milberg, and Burke [11], Wang, Lee, and Wang [12], and Culnan and Armstrong [13]. These researchers provided an early discussion of privacyrelated conceptualizations, theoretical developments, taxonomies, constructs and principles for protecting consumer privacy. Notably, Goodwin's [9] influential study systemically elaborated the definition of consumer privacy. He argued that consumer privacy is consumers' ability to control their personal information in the transaction and consumption process. In contrast, Wang, Lee and Wang [12] underscored the aspect of an individual's right to privacy with regard to the use of personal information. However, the complexity and ambiguity of the concept of consumer privacy has led to very diverse outcomes that lack consensus [14]. A proliferation of subsequent publications has investigated consumerrelated attitudes, perceptions, behavioral consequences and coping strategies as well as the implications of their implementation in the marketing field. Despite this rapidly growing attention, the development of privacy research in the marketing domain is still in a rela- 
tively early stage. We thus provide a literature analysis of consumer privacy research and take a prospective look at the field.

Given the flourishing development of privacy research in the information system field, prior studies have conducted literature reviews [14-17]. However, there are a few limitations that have been overlooked. First, to the best of our knowledge, these literature reviews predominately adopted an information system perspective, making it difficult to evaluate the overall contribution of marketing to information privacy research. Second, all of these reviews overemphasize the systematic delineation of privacy concepts and the relationships among consumer privacy-related constructs such as privacy perception, beliefs, behavioral consequences, and remedies. For example, Smith, Dinev, and Xu [17] provide an interdisciplinary review of recent developments in the domain, and systematically compare and discuss the conceptualization of information privacy, the relationship between information privacy and other constructs, and the contextual nature of these relationships. Third, peer review represents the principal procedure of quality judgment, but it also has deficiencies, such as vulnerability to subjective cognitive limitations [18]. By contrast, the bibliometric approach works well in the general assessment of fields that involve a diverse range of relevant topics [19]. In existing studies, there is an apparent dearth of investigation of the structure and dynamics of consumer privacy research. Fourth, despite the sporadic studies on the review of privacy-specific issues such as the privacy paradox [20], privacy concerns and their measurement [21,22] in recent years, a comprehensive review of information privacy ended in 2011. Although new research themes have emerged since then, there have been no updates. Finally, extant reviews have a relatively ambiguous time window and literature selection. Thus, this article is devoted to filling these research gaps. Specifically, the goal of this research includes four aspects: (1) to portray the co-citation network (e.g., co-citation cluster) in the consumer privacy field; (2) to capture the fundamental transitions and research evolution of the consumer privacy knowledge domain; (3) to identify the landmark articles that have a traction effect on consumer privacy research as a whole; (4) to detect emerging topics of consumer privacy and further suggest opportunities for future research.

The structure of this study is arranged as follows. First, we perform a state-of-the-art review related to consumer privacy through the core dataset. In addition, 2496 publications are investigated in an attempt to clearly see the intellectual landscape of the consumer privacy research domain and the newest research fronts. Specifically, we not only focus on the journal co-citation network, contributing authors and affiliations to obtain a descriptive analysis but also investigate the document co-citation networks, co-occurring keywords, and references with large citation bursts to obtain more detailed information on the intellectual structure, research dynamics, and emerging trends in the domain. Furthermore, we expand our dataset collection by using the expanded citations to acquire a broader landscape, in which 23,171 retrieval results are analyzed. In this section, we mainly extend our understanding of the emerging trends in the consumer privacy field.

\section{Methodology}

\subsection{Data Collection}

When conducting data retrieval, a dilemma arises regarding the trade-off between "recall rate" and "precision rate" [23]. Generally, a higher precision rate is accompanied by a lower recall rate and vice versa. To ensure better retrieval performance, we followed previous research and adopted a strategy of combining "topic term retrieval" and "citation index-based expansion" [24], through which we can fully capture more information. As the world's largest academic information platform, ISI (Institute for Scientific Information) Web of Science has a rich collection of citation indexes representing the citation connections between scholarly research articles, which makes it particularly suitable for our data collection. For the core dataset, the data collection procedure includes several steps as follows (as shown in Figure 1): (1) Database selection. Our datasets were primarily retrieved from the Web of Science (Core Collection), which incorporates a series of citation 
indexes. Given the research theme of our study, we chose three citation indexes, "SCIEXPANDED/SSCI/A\&HCI" databases, which have a collection of more than 12,000 highquality scholarly journals and numerous articles published worldwide. (2) Research topics and time window. Through reviewing substantial literature in the domain, we believe that keywords "consumer privacy" and "customer privacy" are more representative search terms since these two keywords appeared in the early influential works, such as Smith, Milberg, and Burke [11], Wang, Lee, and Wang [12], etc. Therefore, we used the keywords "consumer privacy" or "customer privacy" as the search terms and covered the timespan "all year (1985 to 2019)" to retrieve sample records in the core collection. In addition, only original research articles published in English-language journals were considered. We thus obtained 2690 retrieval results. (3) Additional filters. Less representative record types (e.g., book reviews, research notes, and book chapters) were excluded, and the results were reduced to 2532 articles. (4) Irrelevant record elimination. To validate the data more precisely, we manually reviewed each article to eliminate less relevant sources. Twentyeight irrelevant references were removed, and the retrieval results yielded 2496 records.

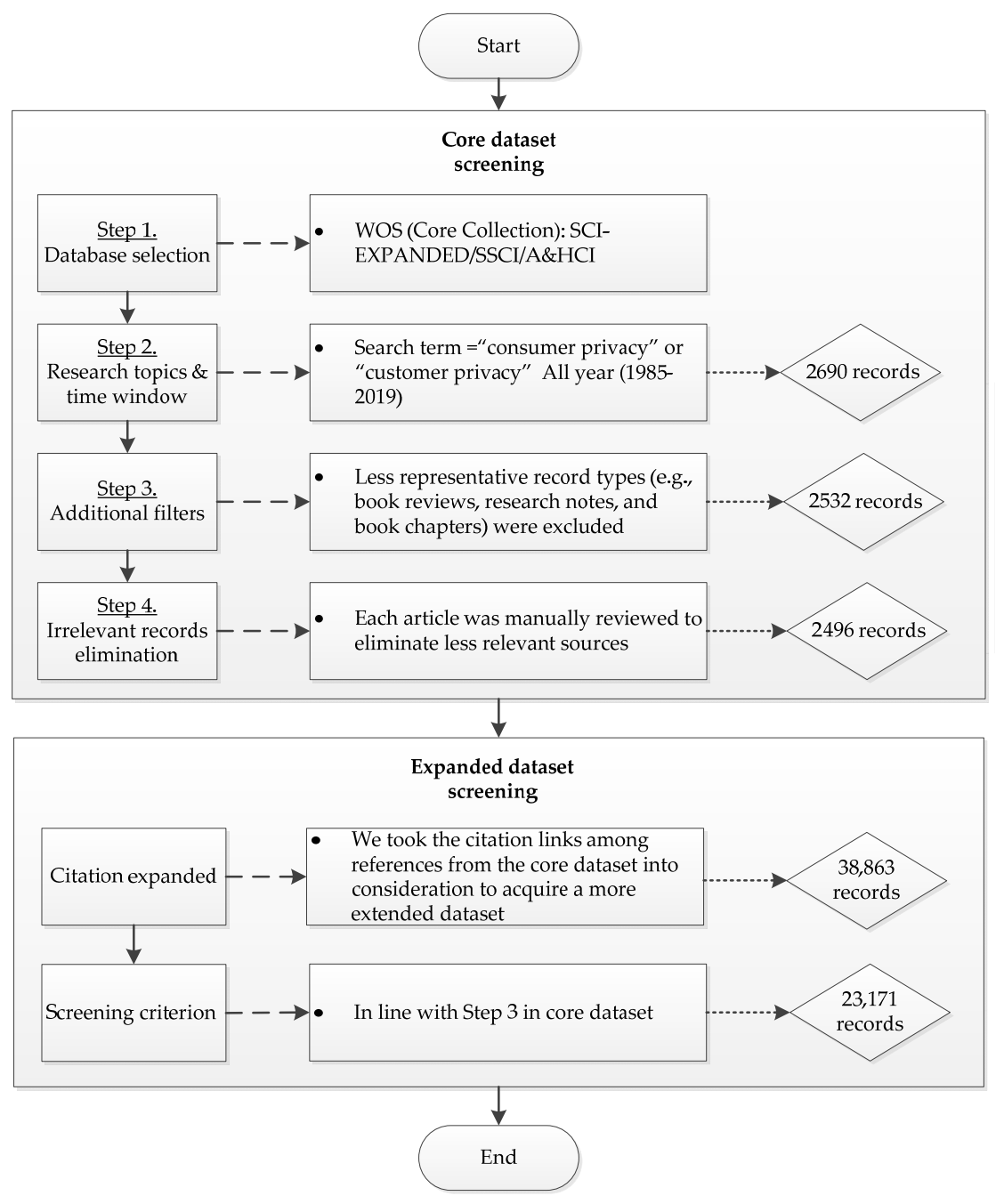

Figure 1. Data collection process.

For the expanded dataset, we took the citation links among references from the core dataset into consideration to acquire a more extended dataset. The screening criteria remained almost consistent with that applied to the core dataset screening. The expanded dataset resulted in 38,863 records, and 23,171 records were used for analysis. 


\subsection{CiteSpace}

This paper adopts bibliometric tool CiteSpace to examine the literature for the following three reasons. First, previous literature reviews applying bibliographic data have proven to be extremely cost- and labor-intensive [25]. CiteSpace has the potential to simplify our review process, and thus improve the quality of reviews. Second, according to Chen [26], CiteSpace innovatively uses citing papers as the intellectual base and cited papers as the research front to build a time-variant mapping network. This tool can help visualize intellectual structures and capture abrupt changes in scientific literature [26]. Third, despite the powerful function of CiteSpace, to the best of our knowledge no investigation has been done to use CiteSpace to analyze consumer privacy literature.

For this research, each bibliographic record result from the search included the article's title, abstract, term, keyword, author, country, institution, journal, cited authors, and cited references. These records enabled us to build an integrated network relation of these articles based on CiteSpace, including author co-citation, regional collaboration, cooccurring keywords, document co-citation, and geospatial visualizations via a set of tools such as pruning (e.g., pathfinder, pruning sliced networks, minimum spanning tree), burst detection, and clusters. Moreover, CiteSpace allows evaluation of a broader knowledge network of this domain rather than the literature per se.

\subsection{Statistical Methods}

Using CiteSpace to carry out the bibliometric analysis is deemed a useful aid in scientific analysis of literature. Due to the advantage of revealing the structural and dynamic patterns and trends of the scientific field [26], this analytic method has received considerable attention in scientometrics, as well as in various other disciplines such as computer science, sociology, and management science. Specifically, the analytic method has three main techniques: co-citation analysis, co-occurring analysis, and structural variation analysis.

Co-citation analysis is a literature-based technique that is often used to explore the intellectual structure of academic fields and the characteristics of academic communities [27]. Small [28] conceptualized co-citation as the frequency with which a pair of publications were cited together by a latter study. In other words, co-citation counts are the numbers of papers that cite the pair. Subsequently, some scholars (e.g., [29,30]) found that highly co-cited pairs of studies can be clustered in a group through co-citation links and that such groups correspond with major research areas. The clustering of co-cited articles formed aggregates representing the size of scientific fields or disciplines. In this study, we mainly use co-citation cluster analysis to display the intensity of connectivity among the topics for which measures of centrality, clustering, and modularity were used [31].

Co-occurring keyword analysis is primarily based on the citation burst algorithm to detect the keyword's statistically significant fluctuations within the corresponding period [32]. The citation burst algorithm was developed to use a two-stage weighted automation model to compute a weight associated with each burst. Specifically, a burst $\left[\mathrm{t}_{1}\right.$, $\mathrm{t}_{2}$ ] can be calculated as $\sum_{t=t_{1}}^{t_{2}}\left(\varphi\left(o, r_{t}, d_{t}\right)-\varphi\left(1, r_{t}, d_{t}\right)\right)$, where $r_{t}$ is the number of terms at the $t_{n}$ that contain the word $\mathrm{u}$, and $d_{t}$ is the total number of terms at the $t_{n}$ [32]. These co-occurring keywords represent the network of conceptual relations from the viewpoint of scholars active in the field. When some keywords were found to have an upsurge of use from others at a particular moment in time, we regarded these keywords as receiving increased attention in the research network.

Structural variation analysis measures a research field's structural change, which plays an overarching role in bridging previously disjoint bodies of knowledge $[26,33]$. More specifically, the structural variation reflects two dimensions: betweenness centrality and sigma. Betweenness centrality reflects the degree to which a point dominates the communication path between other points on the minimal path [34]. In this article, betweenness centrality allows us to accurately and easily identify potential pivotal points of 
paradigm shift in evolving scientific networks [19,31]. In other words, we use the betweenness centrality of a node to identify pathways between different thematic clusters, which implies that an article with the highest centrality value reflects its importance in connecting the preceding clusters with the following clusters, namely, the intellectual turning points. Sigma is used to measure scientific novelty, which is a combined measure of citation burst and structural centrality and is calculated as (centrality +1$)^{\text {burstness }}$ [26].

\section{Results}

\subsection{The Landscape from the Core Dataset}

\subsubsection{The Number of Publications per Year}

Figure 2 illustrates the time trends and distribution of consumer privacy articles published from 1997 to 2019. Three results can be derived. First, there has been a steady increase in consumer privacy research over the past two decades. Second, only a small number of studies on this topic were published before 2000, while there appears to be a slow growth trend in the annual numbers of published articles from 2001 to 2010 . We can see sharp growth during the years 2010 to 2019. This trend is closely related to changes in the public's demand for personal information privacy and security.

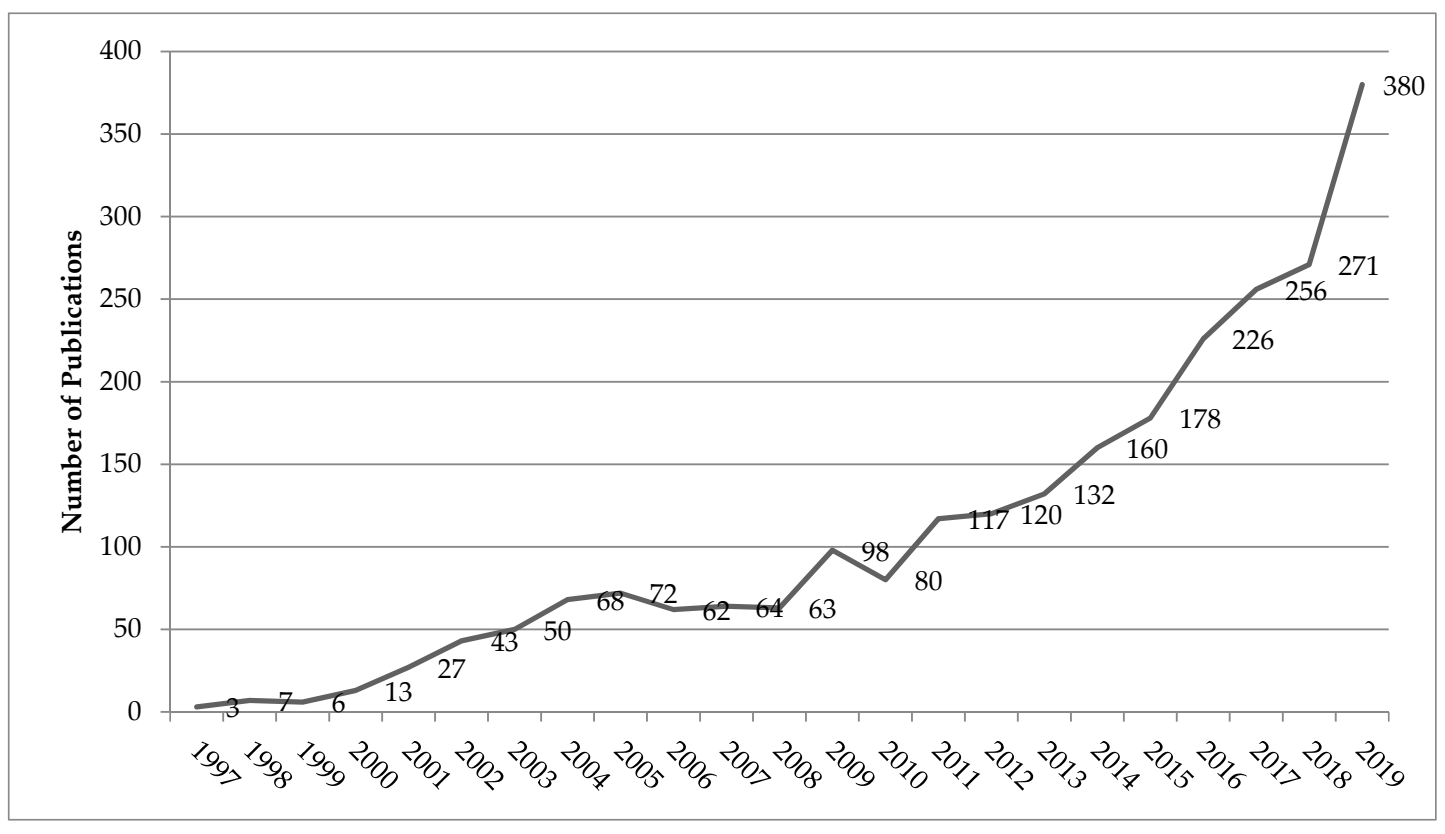

Figure 2. Annual distribution of the number of articles across the period studied (1997-2019).

\subsubsection{Distribution across Journals and Disciplines}

As Leydesdorff and Rafols [35] noted, we should regard the decomposition of disciplinary structures as the first effort to gain insight into a research field. In order to identify journal and disciplinary categories, we used the Analyze Results tool, which is one of the features that sets Web of Science apart from other comparable databases. This tool allows us to segment and examine search results by categories such as journals, disciplines, and more. We first start with the most contributing journals within the domain of consumer research between 1997 and 2019. 334 journals were included in our dataset only if they had at least 10 co-citations. The top 10 journals, ranked by frequency involving consumer privacy, were as follows: Computers in Human Behavior (55 articles) was the main peerreviewed journal to publish works about consumer privacy, followed by Lecture Notes in Computer Science (49 articles), IEEE Transactions on Smart Grid (38 articles), IEEE Access (30 articles), Computer Law Security Review (29 articles), Journal of Business Research (26 articles), Journal of Consumer Affairs (25 articles), Electronic Commerce Research 
and Applications (23 articles), Internet Research (23 articles), and International Journal of Mobile Communications (22 articles). We can thus conclude that: First, this list reveals the multidisciplinary characteristics in the field of consumer privacy research; second, from the perspective of the distribution of disciplines, Computer Science Information Systems (accounting for $24.29 \%$ of the total articles), Business (18.68\%), and Management (10.78\%) made the greatest contributions to this field. These characteristics represent that research on consumer privacy could provide a broader perspective on the development of privacy.

\subsubsection{The Most Prolific Regions, Institutions and Authors}

Table 1 lists the most prolific regions, institutions, and authors in consumer privacy research. It shows that the USA was the most prolific region with 1149 publications, followed by China with 271 publications and the UK with 185 publications. With regard to institutions, Purdue University and University of Massachusetts are the most productive institutions with 26 publications. In terms of the most prolific authors, George R Milne from University of Massachusetts Amherst and Xu Heng from Kogod School of Business at American University are the top two most published authors in the field of consumer privacy, while Alessandro Acquisti, Rainu Kaushal, and Paul Benjamin Lowry tied for third place. Interestingly, a highly consistent correlation can be observed among regions, institutions and authors.

Table 1. Most prolific regions, institutions and authors in consumer privacy research.

\begin{tabular}{cccccc}
\hline Region & Freq. & Institution & Freq. & Author & Freq. \\
\hline USA & 1126 & Purdue Univ & 26 & George R Milne & 11 \\
Peoples' Republic of & 268 & Univ Massachusetts & 26 & Xu Heng & 10 \\
China & 182 & Univ Sydney & 25 & Alessandro Acquisti & 9 \\
UK & 160 & Univ Michigan & 21 & Rainu Kaushal & 9 \\
Australia & 148 & Penn State Univ & 21 & Paul Benjamin Lowry & 9 \\
Germany & 137 & Natl Univ Singapore & 21 & Dan J Kim & 8 \\
South Korea & 120 & Harvard Univ & 20 & Pouyan Esmaeilzadeh & 7 \\
Canada & 106 & Univ Wisconsin & 20 & Younghoon Chang & 7 \\
Taiwan, China & 93 & Florida int Univ & 20 & Cristian Morosan & 7 \\
Spain & 72 & Univ Calif Berkeley & 19 & May O Lwin & 7 \\
Italy & & & &
\end{tabular}

\subsubsection{Co-Occurring Keyword in Consumer Privacy Research}

Table 2 presents a list of the top 30 keywords with the strongest bursts in consumer privacy. Strength denotes the degree of connectivity and centrality in the complete relationship among keywords. In other words, it can be deemed an indicator of the active use of keywords. The red bar represents how long the relevant keywords' burst status lasts. For example, the keyword "Internet privacy" shows the characteristics of high-frequency usage during the years 2001-2009. In essence, the bursts of certain keywords within a certain period of time highlight the evolution of consumer privacy research and uncover recent research trends.

In an earlier stage, the emergence of online technologies such as the Internet and e-commerce awakened consumers and academia to the potential threat of personal privacy. This is not surprising because some keywords, including "internet privacy", "cryptography", "trustworthiness", and "TAM (technology acceptance model)", present the strongest citation bursts. With the arrival of the web 2.0 era, which was characterized by greater user interactivity in the late 2000s, firms faced a situation in which consumers were more willing to interact with them by participating and collaborating in the network system. To manage the customer relationship, numerous firms have further commercially explored consumer behavior. Thus, keywords such as "website", "usability" "commitment", "consumer trust", and the like have elicited much interest in the academic field. More recently, keywords such as "privacy calculus", "willingness", "access control", "Internet banking", "social media", "algorithm", "electronic health record", "smartphone", "big data", and "perceived 
value" have shown a significant presence. Such trends might be attributed to the development of information technology, especially its widespread application in a variety of consumer-related service sectors. In summary, we can clearly notice several major shifts of research focus in consumer privacy literature.

Table 2. Summary of the top 30 keywords based on citation burst strength.

\begin{tabular}{|c|c|c|c|c|}
\hline Keywords & Strength & Begin & End & 1997-2019 \\
\hline Internet privacy & 4.37 & 2001 & 2009 & 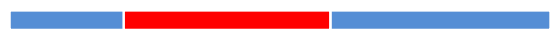 \\
\hline Cryptography & 3.35 & 2001 & 2008 & $e^{2}$ \\
\hline Trustworthiness & 4.71 & 2003 & 2007 & 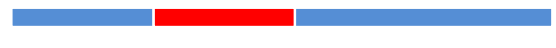 \\
\hline TAM & 3.6 & 2003 & 2009 & n \\
\hline RFID & 5.75 & 2006 & 2012 & 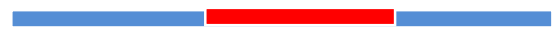 \\
\hline Website & 4.81 & 2008 & 2013 & ש \\
\hline Usability & 3.84 & 2009 & 2013 & 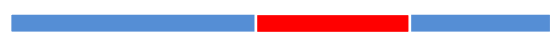 \\
\hline Commitment & 3.55 & 2009 & 2011 & 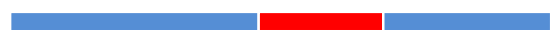 \\
\hline Consumer trust & 4.16 & 2010 & 2014 & 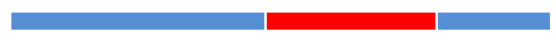 \\
\hline Privacy calculus & 4.57 & 2011 & 2015 & 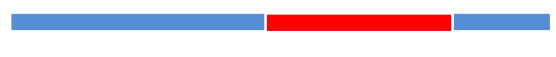 \\
\hline Willingness & 3.62 & 2011 & 2015 & 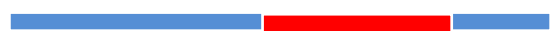 \\
\hline Access control & 3.4 & 2011 & 2014 & 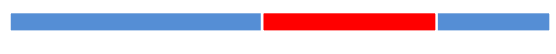 \\
\hline Cloud computing & 7.57 & 2012 & 2017 & 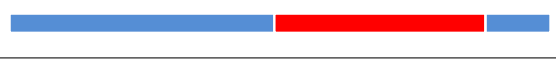 \\
\hline Personal information & 5.04 & 2012 & 2017 & 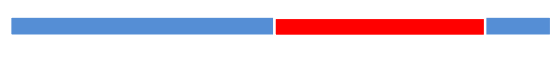 \\
\hline Internet banking & 3.34 & 2012 & 2017 & D. \\
\hline Social media & 5.39 & 2013 & 2019 & 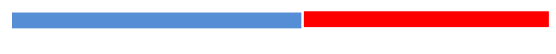 \\
\hline Market & 3.59 & 2013 & 2019 & 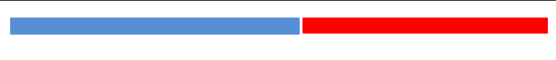 \\
\hline Algorithm & 4.9 & 2014 & 2019 & 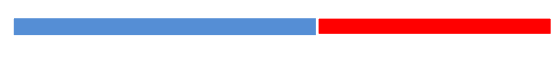 \\
\hline Power & 4.39 & 2014 & 2017 & 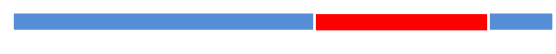 \\
\hline Law & 3.58 & 2014 & 2016 & 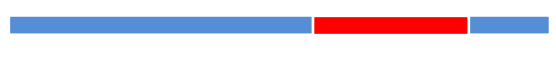 \\
\hline Electronic health record & 3.5 & 2014 & 2017 & 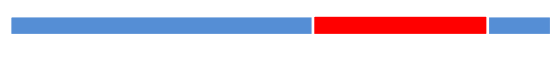 \\
\hline Smartphone & 3.39 & 2014 & 2016 & 1 \\
\hline Secure & 3.19 & 2014 & 2019 & 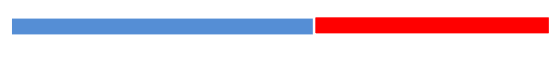 \\
\hline Big data & 11.04 & 2015 & 2019 & 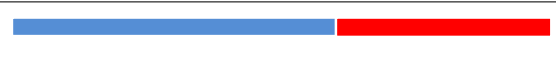 \\
\hline Social networking site & 6.06 & 2015 & 2017 & $\boldsymbol{q}$ \\
\hline Facebook & 4.88 & 2015 & 2019 & 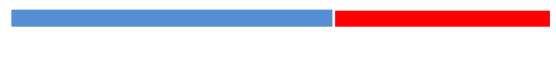 \\
\hline Perceived value & 3.93 & 2015 & 2019 & - \\
\hline Intention & 8.15 & 2016 & 2019 & 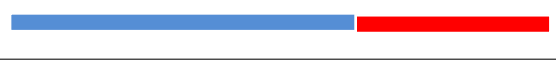 \\
\hline Word of mouth & 6.22 & 2016 & 2019 & 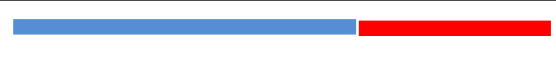 \\
\hline Challenge & 3.7 & 2016 & 2019 & 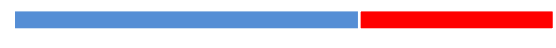 \\
\hline
\end{tabular}

Note: Strength denotes the degree of connectivity and centrality in the complete relationship among keywords. 


\subsubsection{Thematic Clusters in Consumer Privacy Research}

Table 3 presents a detailed overview of co-citation clusters by the size of the references included. Every cluster's label was algorithmically chosen from the citing articles' title and abstract by the log-likelihood ratio weighting algorithm (LLR), which is a measure that calculates the weighting coefficients of references in the cluster [36]. The silhouette metric is used to estimate the uncertainty involved in identifying the nature of a cluster [36]. The score ranges from -1 to 1 . A score close to 1 suggests a cluster that is more separated from other clusters. The average year shows the recentness of these clusters, and the coverage value indicates the proportion of cited members of a cluster that the citing article has cited. The citing articles are regarded as the intellectual base [26]. These characteristics together further reflect the research evolution of consumer privacy. Given that small clusters are less representative due to the few citing behaviors, we list only those clusters with sizes greater than 50 references, namely, a total of 12 clusters. Clusters \#0, \#1,\#2, \#3, and \#4 can be identified as the largest clusters and are very widely accepted research themes within the corresponding period. In contrast, Clusters \#0, \#1, \#3, and \#6 are deemed to be the most recently formed clusters with citation bursts. Then, we select representative citing papers with coverage beyond $10 \%$ as our critical research focus. For example, Karimov's [37] article in cluster \#0 cited $14 \%$ of the references of all 285 citations in the cluster, which makes it the most relevant citing document associated with the cluster.

It is evident that the representative terms "initial trust", "electronic banking", and "user acceptance" dominate the largest cluster \#0. A total of 285 references with an average year of 2011 are included in this cluster. A great proportion of the studies in this cluster explore the mechanism of the inherent influence of privacy and security perception on consumer adoption or user acceptance of digital services, involving e-banks [38], smart home services [39], and smart glasses [40]. This finding indicates that the commercial application of technology elicits the concern for privacy security among consumers.

As the second largest and recently formed cluster, Cluster \#1, labeled "data privacy", "digital market manipulation", and "information technology", contains 263 members with an average year of 2012. The research with the largest coverage in this cluster is by Peppet SR [41], Calo R [42], and Porat A [43]. These authors attempt to incorporate the idea of digital market manipulation and propose that the development of digital technologies offers companies more digital means to approach their consumers anytime and anywhere instead of waiting passively for the market response. Accordingly, social impact and ethical issues (e.g., social welfare, discrimination) were generated due to unforeseen actions or unauthorized use by companies to target consumers more precisely than in the past. The issue of how to manage a balance between social-economic welfare and the interests of consumers appears to be a great challenge for future regulators and legislators [44,45] and has emerged as a prominent area of research interest.

Cluster \#3 is the third recently formed cluster with an average year of 2010. Labeled "integrated framework" and "online information privacy research", this cluster has 128 references. This cluster primarily provides the theoretical basis for this field and may shed light on further research. For example, many studies propose an integrated theoretical framework to understand context-specific antecedents and outcomes of privacy concerns (e.g., [46-52]). An implication for further research is thus to exploit context and contextual differences in managing consumer privacy. 
Table 3. Representative papers of main clusters.

\begin{tabular}{|c|c|c|c|c|c|}
\hline Cluster \# & Size & Silhouette & $\begin{array}{l}\text { Mean } \\
\text { Year }\end{array}$ & Citing Papers & $\begin{array}{c}\text { Coverage } \\
\%\end{array}$ \\
\hline $\begin{array}{l}\# 0 \\
\text { Initial trust; } \\
\text { Electronic banking; } \\
\text { User adoption }\end{array}$ & 285 & 0.927 & 2011 & $\begin{array}{l}\text { Karimov FP (2014). The effect of website design } \\
\text { dimensions on initial trust: A synthesis of the } \\
\text { empirical literature. } \\
\text { Xu H (2011). Information privacy concerns: Linking } \\
\text { individual perception with institutional privacy } \\
\text { assurances. } \\
\text { Zhao T (2011). The impact of privacy concern on } \\
\text { user adoption of location-based services. } \\
\text { Liao CC (2011). Examining the impact of privacy, } \\
\text { trust and risk perceptions beyond monetary } \\
\text { transactions: An integrated model. } \\
\text { Martin KE (2012). Diminished or just different? A } \\
\text { factorial vignette study of privacy as a social contact. } \\
\text { Treiblmaier H (2011). Trust and perceived risk of } \\
\text { personal information as antecedents of online } \\
\text { information disclosure: Results from three countries. }\end{array}$ & $\begin{array}{l}13 \\
12 \\
11 \\
11\end{array}$ \\
\hline $\begin{array}{c}\# 1 \\
\text { Data privacy; } \\
\text { Digital market } \\
\text { manipulation; } \\
\text { Information technology }\end{array}$ & 263 & 0.967 & 2012 & $\begin{array}{l}\text { Peppet SR (2014). Regulating the internet of things: } \\
\text { First steps toward managing discrimination, privacy, } \\
\text { security, and consent. } \\
\text { Calo R (2013). Digital market manipulation. } \\
\text { Porat A (2014). Personalizing default rules and } \\
\text { disclosure with big data. }\end{array}$ & $\begin{array}{l}19 \\
17 \\
11\end{array}$ \\
\hline $\begin{array}{c}\# 2 \\
\text { Intention to transact } \\
\text { online; } \\
\text { Seller trust; } \\
\text { Future direction }\end{array}$ & 147 & 0.916 & 2000 & $\begin{array}{l}\text { Belanger F (2002). Trustworthiness in electronic } \\
\text { commerce: the role of privacy, security, and site } \\
\text { attributes. } \\
\text { Shankar V (2002). Online trust: a stakeholder } \\
\text { perspective, concepts, implications, and future } \\
\text { directions. } \\
\text { George JF (2004). The theory of planned behavior } \\
\text { and internet purchasing. } \\
\text { Taylor DG (2010). Has e-marketing come of age? } \\
\text { Modeling historical influences on post-adoption era } \\
\text { Internet consumer behaviors. }\end{array}$ & $\begin{array}{l}18 \\
15\end{array}$ \\
\hline $\begin{array}{l}\# 3 \\
\text { Integrated framework; } \\
\text { Online information } \\
\text { privacy research; }\end{array}$ & 128 & 0.913 & 2010 & $\begin{array}{l}\text { Liao CC (2011). Examining the impact of privacy, } \\
\text { trust and risk perceptions beyond monetary } \\
\text { transactions: An integrated model. } \\
\text { Ozdemir ZD (2017). Antecedents and outcomes of } \\
\text { information privacy concerns in a peer context: An } \\
\text { exploratory study } \\
\text { Li Y (2012). Theories in online information privacy } \\
\text { research: A critical review and an integrated } \\
\text { framework }\end{array}$ & 12 \\
\hline $\begin{array}{l}\quad \# 4 \\
\text { Digital marketing; } \\
\text { Interactive media; } \\
\text { Privacy concern }\end{array}$ & 110 & 0.98 & 2003 & $\begin{array}{l}\text { Andrejevic M (2002). The work of being watched: } \\
\text { Interactive media and the exploitation of } \\
\text { self-disclosure. } \\
\text { Ashworth L (2006). Marketing dataveillance and } \\
\text { digital privacy: Using theories of justice to } \\
\text { understand consumers' online privacy concerns. } \\
\text { Luo XM (2002). Trust production and privacy } \\
\text { concerns on the Internet: A framework based on } \\
\text { relationship marketing and social exchange theory. }\end{array}$ & 18 \\
\hline
\end{tabular}


Table 3. Cont.

\begin{tabular}{|c|c|c|c|c|c|}
\hline Cluster \# & Size & Silhouette & $\begin{array}{c}\text { Mean } \\
\text { Year }\end{array}$ & Citing Papers & $\begin{array}{c}\text { Coverage } \\
\%\end{array}$ \\
\hline $\begin{array}{l}\# 5 \\
\text { Predicting etail quality; } \\
\text { Online information; } \\
\text { Online service }\end{array}$ & 102 & 0.924 & 2005 & $\begin{array}{l}\text { Wolfinbarger (2003). EtailQ: Dimensionalizing, } \\
\text { measuring and predicting etail quality. } \\
\text { Lwin MO (2003). A model integrating the } \\
\text { multidimensional developmental theory of privacy } \\
\text { and theory of planned behavior to examine } \\
\text { fabrication of information online. } \\
\text { Liu CT (2010). Measuring user perceived service } \\
\text { quality of online auction sites } \\
\text { Xu B (2010). Factors affecting consumer behaviors in } \\
\text { online buy-it-now auctions }\end{array}$ & $\begin{array}{l}20 \\
11\end{array}$ \\
\hline $\begin{array}{c}\# 6 \\
\text { Health information; } \\
\text { E-medicine; } \\
\text { Personal health records }\end{array}$ & 100 & 0.98 & 2010 & $\begin{array}{l}\text { Brann M (2002). E-medicine and health care } \\
\text { consumers: Recognizing current problems and } \\
\text { possible resolutions for a safer environment. } \\
\text { Vodicka E (2013). Online access to doctors' notes: } \\
\text { Patient concern about privacy. } \\
\text { Zarcadoolas C (2013). Consumers' perceptions of } \\
\text { patient-accessible electronic medical records }\end{array}$ & $\begin{array}{l}19 \\
11\end{array}$ \\
\hline $\begin{array}{c}\# 7 \\
\text { Security risk; } \\
\text { Consumer perception; } \\
\text { Online privacy policies }\end{array}$ & 98 & 0.949 & 1999 & $\begin{array}{l}\text { Miyazaki AD (2001). Consumer perceptions of } \\
\text { privacy and security risks for online shopping. } \\
\text { Anton AI (2004). A requirements taxonomy for } \\
\text { reducing web site privacy vulnerabilities. } \\
\text { Hoy MG (2003). Consumer privacy and security } \\
\text { protection on church web sites: Reasons for concern. } \\
\text { Earp JB (2005). Examining Internet privacy policies } \\
\text { within the context of user privacy values. }\end{array}$ & $\begin{array}{l}20 \\
15 \\
10\end{array}$ \\
\hline $\begin{array}{l}\text { \#8 } \\
\text { Literature review; } \\
\text { Security challenge; } \\
\text { Empirical study }\end{array}$ & 91 & 0.961 & 2005 & $\begin{array}{l}\text { Beldad A (2010). How shall I trust the faceless and } \\
\text { the intangible? A literature review on the } \\
\text { antecedents of online trust. } \\
\text { Karimov FP (2014). An examination of trust } \\
\text { assurances adopted by top Internet retailer: } \\
\text { Unveiling some critical determinants. } \\
\text { Simth HJ (2011). Information privacy research: An } \\
\text { interdisciplinary review. } \\
\text { Lee SM (2007). Rfid based ubiquitous commerce and } \\
\text { consumer trust. } \\
\text { Ozdemir ZD (2017). Antecedents and outcomes of } \\
\text { information privacy concerns in a peer context: An } \\
\text { exploratory study. }\end{array}$ & $\begin{array}{l}14 \\
12 \\
10\end{array}$ \\
\hline $\begin{array}{c}\# 9 \\
\text { Privacy calculus; } \\
\text { Information disclosure; }\end{array}$ & 80 & 0.948 & 2009 & $\begin{array}{l}\text { Dinev T (2006). An extended privacy calculus model } \\
\text { for e-commerce transactions. } \\
\text { Xu H (2009). The role of push-pull technology in } \\
\text { privacy calculus: The case of location-based services. } \\
\text { Mai B (2010). No free lunch: Price premium for } \\
\text { privacy seal-bearing vendors. }\end{array}$ & $\begin{array}{l}15 \\
12 \\
10\end{array}$ \\
\hline $\begin{array}{l}\qquad \# 10 \\
\text { Building consumer trust; } \\
\text { Trust building model; }\end{array}$ & 79 & 0.968 & 2004 & $\begin{array}{l}\text { Mcknight DH (2002). The impact of initial consumer } \\
\text { trust on intentions to transact with a web site: A } \\
\text { trust building model. } \\
\text { Mukherjee A (2007). Role of electronic trust in online } \\
\text { retailing: A re-examination of the commitment-trust } \\
\text { theory. } \\
\text { Aguirre E (2015). Unraveling the Personalization } \\
\text { Paradox: The Effect of Information Collection and } \\
\text { Trust-Building Strategies on Online Advertisement } \\
\text { Effectiveness. }\end{array}$ & 28 \\
\hline
\end{tabular}


Table 3. Cont

\begin{tabular}{|c|c|c|c|c|c|}
\hline Cluster \# & Size & Silhouette & $\begin{array}{c}\text { Mean } \\
\text { Year }\end{array}$ & Citing Papers & $\begin{array}{c}\text { Coverage } \\
\%\end{array}$ \\
\hline $\begin{array}{c}\# 11 \\
\text { Online privacy }\end{array}$ & \multirow[b]{2}{*}{66} & \multirow[b]{2}{*}{0.96} & \multirow[b]{2}{*}{2009} & $\begin{array}{l}\text { Metzger MJ (2010). Public opinion and policy } \\
\text { initiatives for online privacy protection. }\end{array}$ & 28 \\
\hline $\begin{array}{c}\text { protection; } \\
\text { Policy initiative; } \\
\text { Privacy regulation }\end{array}$ & & & & $\begin{array}{l}\text { Goldfarb A (2011). Privacy regulation and online } \\
\text { advertising. }\end{array}$ & 10 \\
\hline
\end{tabular}

Notes: Size: the number of members in each cluster; Silhouette: a metric of a cluster measures the uncertainty involved in identifying the nature of a cluster, and a score (from -1 to 1) close to 1 suggests a cluster that is more separated from other clusters; Mean Year: the recentness of these clusters; Citing articles: the intellectual base; Coverage: the proportion of cited members of a cluster that the citing article has cited 3.1.5. Thematic variation in the landscape.

Cluster \#6 is labeled "health information", "e-medicine" and "personal health records". This cluster explores issues related to consumers' or patients' perceptions of their health information or their records being exchanged [53,54] and how they respond to the underlying risk of the loss of their privacy [55]. This cluster highlights the trend of data usage and privacy concerns in the medical field.

Cluster \#2 makes an inquiry into the impact of the information privacy attitude taken by the service provider on the consumer's behavioral intentions (e.g., [56,57]). Cluster \#4 focuses on consumer privacy concerns and the merits of the application of information technology, such as making markets more efficient. Cluster \#5 studies the measure of electronic service quality (e.g., B2C platform, ATM, etc.), users' perceptions, and the resulting user behavior. Cluster \#7 mainly explores the relationship between various individual-level and firm-level factors and their impacts on consumers' privacy perception. Cluster 8 concentrates on the analysis of the literature review. Cluster \#9 focuses on consumer privacy calculus. The literature shows that a privacy calculus (risk-benefit evaluation) exists when consumers decide to proceed with information disclosure $[47,58]$, purchase behavior [48,59], and user adoption of new digital services [52,60-62]. Cluster \#10 addresses how to reduce privacy concerns by building consumer trust. Cluster \#11 emphasizes the importance of government or public organizations' policies on regulating privacy security.

To sum up, each cluster reflects a thematic concentration, which can help us to further understand the thematic trends associated with consumer privacy. More importantly, these clustering results revealed in our study suggests that research on consumer privacy has a long way to go to comprehend consumers' complicated decision-making process when it comes to personal privacy.

Table 4 shows top ten structurally variational references in the synthesized network. These works are characterized by their traction effect on the entire consumer privacy research field since they can be considered landmark studies connecting the different aggregated groups. The descending order parameter is used to sort these references. The article with the highest betweenness centrality in our dataset is Reagle J [63], followed by Earp JB [64]. The third is the article by Bansal G [65]. The articles in the fourth to tenth positions are Brandimarte L [66], Moores T [67], Tang Z [68], John LK [69], Pavlou PA [70], Norberg PA [71], and Acquisti A [72]. Additionally, we list the 10 cited articles with the highest sigma. The top three highest sigma values are for the articles by Smith HJ [17], Dinev T [59], and Bansal G [65]. These works are identified as being more likely to represent novel ideas due to their transformative potential. For example, Bansal G [65]'s research opened up a new prospect for studying health information privacy by taking personal dispositions into consideration. 
Table 4. Top 10 betweenness centrality and sigma references.

\begin{tabular}{cccc}
\hline References & Betweenness Centrality & References & Sigma \\
\hline Reagle J, 1999, Commun ACM & 0.09 & Smith HJ, 2011, MIS Quart & 1.69 \\
Earp JB, 2005, Commun ACM & 0.08 & Dinev T, 2006, Infor Sys Res & 1.56 \\
Bansal G, 2010, Decis Sup Syst & 0.06 & Bansal G, 2010, Decis Supp Syst & 1.49 \\
Brandimarte L, 2013, Soc Psy Pers Sc & 0.06 & Tang ZL, 2008, J Manage Info S & 1.44 \\
Moores T, 2005, Commun ACM & 0.05 & Brandimarte L, 2013, Soc Psy Pers Sc & 1.42 \\
Tang Z, 2008, J Manag Infor Syst & 0.04 & Hui KL, 2007, MIS Quart & 1.38 \\
John LK, 2011, J Consum Res & 0.04 & John LK, 2011, J Consum Res & 1.37 \\
Pavlou PA, 2003, Int J Elec Com & 0.04 & Earp JB, 2003, Commun ACM & 1.35 \\
Norberg PA, 2007, J Consum Aff & 0.04 & Malhotra NK, 2004, Info Syst Res & Acquisti A, 2013, J Legal Stud \\
Acquisti A, 2013, J Legal Stud & 0.04 & &
\end{tabular}

\subsubsection{Emerging Trend Identification}

Citation bursts have been successfully applied to capture the sharp increase in a relevant research interest. An upsurge in the frequency of a study's citation over a period of time is seen as a mark of academic focus, which implies an underlying research trend [24]. Therefore, we adopt citation burst detection to perform emerging trend identification. Table 5 provides a list of the top 45 references that have the strongest citation bursts. The dark blue bar represents the years in which articles received slight increases in citations, while the red bar shows that citations rise sharply. In order to provide insight into these references, we discuss only those papers with the greatest link strength that start to burst in the same year.

Table 5. Top 45 references with the strongest citation bursts.

\begin{tabular}{|c|c|c|c|c|}
\hline References & Str. & Begin & End & 1997-2019 \\
\hline Culnan MJ. 1999, Organ Sci & 3.76 & 2001 & 2005 & $=\mathbf{n}$ \\
\hline Caudill EM. 2000, J Pub Poli Mark & 3.69 & 2001 & 2004 & 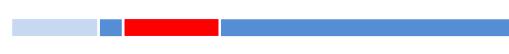 \\
\hline Federal Trade Com. 2000, Priv Onl & 3.45 & 2001 & 2005 & $\square=$ \\
\hline Sheehan KB. 1999, J Advertising & 14.56 & 2002 & 2005 & $\square$ \\
\hline Hoffman DL. 1999, Commu ACM & 13.75 & 2002 & 2005 & 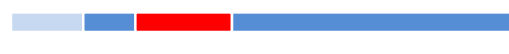 \\
\hline Urban GL. 2000, Sloan Manag Rev & 10.14 & 2002 & 2005 & 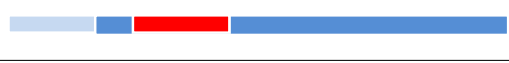 \\
\hline Miyazaki AD. 2002, J Consum Aff & 5.92 & 2005 & 2008 & 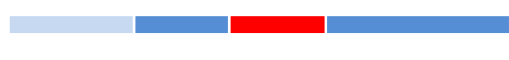 \\
\hline Luo XM. 2002, Ind Market Manag & 4.34 & 2005 & 2008 & +2 \\
\hline Milne GR. 2004, J Consum Aff & 10.75 & 2006 & 2009 & $\ln ^{2}$ \\
\hline Milne GR. 2004, J Interact Mark & 10.18 & 2006 & 2009 & $x^{2}$ \\
\hline Malhotra NK. 2004, Info Syst Res & 8.84 & 2006 & 2009 & 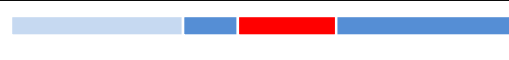 \\
\hline Dinev T. 2006, Info Syst Res & 15 & 2007 & 2011 & 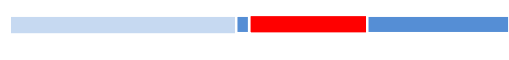 \\
\hline Awad NF. 2006, MIS Quart & 8.77 & 2007 & 2011 & un \\
\hline Chellappa RK. 2005, Info Tech Ma & 8.58 & 2007 & 2009 & 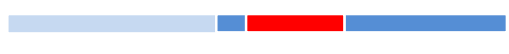 \\
\hline Dinev T. 2005, Int J Electron Com & 7.39 & 2007 & 2011 & 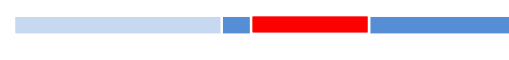 \\
\hline Flavian C. 2006, Ind Man Data Sys & 7.22 & 2007 & 2011 & +1 \\
\hline Bart Y. 2005, J Marketing & 6.82 & 2007 & 2010 & n \\
\hline
\end{tabular}


Table 5. Cont.

\begin{tabular}{|c|c|c|c|c|}
\hline References & Str. & Begin & End & 1997-2019 \\
\hline Pan Y. 2006, J Retailing & 10.02 & 2008 & 2011 & $\ln ^{2}$ \\
\hline Kim DJ. 2008, Decis Support Syst & 9.34 & 2008 & 2013 & $x^{2}$ \\
\hline Schlosser AE. 2006, J Marketing & 8.22 & 2008 & 2011 & $\ln ^{2}$ \\
\hline Pavlou PA. 2007, MIS Quart & 4.93 & 2009 & 2012 & 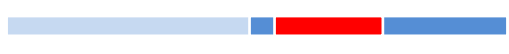 \\
\hline Tang ZL, 2008, J Manag Info Syst & 4.21 & 2009 & 2014 & |n \\
\hline Son JY. 2008, MIS Quart & 4.01 & 2009 & 2012 & ntan \\
\hline Goldfarb A. 2011, Manage Sci & 7.41 & 2011 & 2016 & 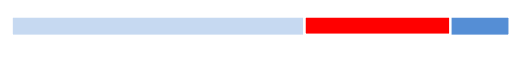 \\
\hline Xu H. 2009, J Manage Info Syst & 7.12 & 2011 & 2014 & 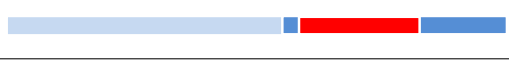 \\
\hline Bansal G. 2010, Decis Support Syst & 6.5 & 2011 & 2015 & 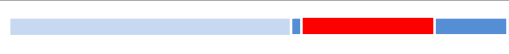 \\
\hline Smith HJ. 2011, MIS Quart & 18.65 & 2012 & 2016 & 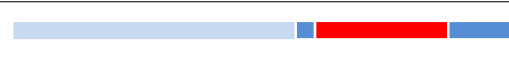 \\
\hline John LK. 2011, J Consum Res & 7.43 & 2012 & 2015 & 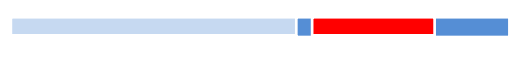 \\
\hline Ohm P, 2010, UCLA Law Rev & 6.71 & 2012 & 2015 & 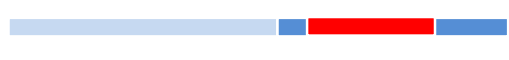 \\
\hline Hair JF, 2010, Multivariate Data An & 4.65 & 2012 & 2015 & $\boldsymbol{l}$ \\
\hline Tsai JY. 2011, Info Syst Res & 14.64 & 2013 & 2016 & (1) \\
\hline Pavlou PA. 2011, MIS Quart & 11.1 & 2013 & 2016 & (1) \\
\hline Belanger F. 2011, MIS Quart & 10.59 & 2013 & 2016 & 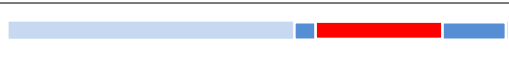 \\
\hline Xu H, 2011, Decis Support Syst & 10.08 & 2013 & 2016 & ang \\
\hline Garcia FD. 2011, Lect Note Compu Sc & 6.55 & 2013 & 2016 & $1=$ \\
\hline Kursawe K. 2011, Lect Note Compu Sc & 5.03 & 2013 & 2016 & an \\
\hline Youn S. 2009, J Consum Aff & 8.17 & 2014 & 2017 & ran \\
\hline Mothersbaugh DL. 2012, J Serv Res & 7.14 & 2014 & 2019 & 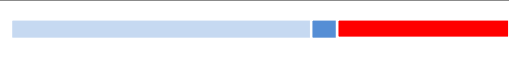 \\
\hline Brandimarte L. 2013, Soc Psyc Per & 5.64 & 2014 & 2019 & 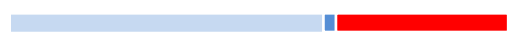 \\
\hline Li Y. 2012, Decis Supp Syst & 5.59 & 2014 & 2019 & (29) \\
\hline Tucker CE. 2014, J Marketing Res & 15.8 & 2015 & 2019 & 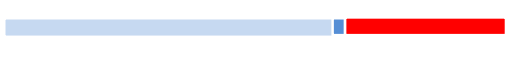 \\
\hline Dinev T. 2013, Eur J Info Syst & 9.4 & 2015 & 2019 & प्रा \\
\hline Hann IH. 2007, J Manage Info Sys & 7.83 & 2015 & 2019 & 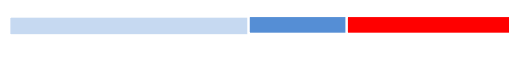 \\
\hline Keith MJ. 2013, Int J Hum-Comput St & 5.74 & 2015 & 2019 & (n) \\
\hline Acquisti A. 2006, Lect Not Comp S & 5.74 & 2015 & 2019 & b \\
\hline
\end{tabular}

From 2002 to 2019, researchers focused on considering the issue of consumers' online trust building [73,74]; exploring the role that privacy regulation plays in raising online firms' privacy-related practices and affecting consumers' judgment [75,76]; examining the extent to which consumers are willing to control their personal information and whether privacy attitudes, offline data behaviors, online experience and consumer background predict the tendency to protect privacy [77]; demonstrating consumers' complicated decisionmaking process when involving personal privacy [59]; offering an interdisciplinary review of privacy-related research [17]; proposing the major driving factors for the uncertainty perception of $\mathrm{B} 2 \mathrm{C}$ e-commerce adoption [78]; understanding whether the explicit display 
of privacy information will affect consumers' consideration on their privacy and resultant behavior [79]; studying the theoretical correlation between privacy concerns and behavioral reactions in the online environment $[13,80,81]$.

In light of the above discussion, the collection of these studies reveals distinct trends. First, early studies examined the theoretical relationship between diverse constructs and privacy-related proxies (e.g., trust, perceptions, beliefs, and attitudes) to shed light on what matters to consumers. Representative articles by Hoffman, Novak, and Peralta [82], Phelps, Nowak and Ferrell [50], Milne, Rohm and Bahl [77], Dinev and Hart [59], and Pan and Zinkhan [74] were thus identified as having the greatest citation bursts, which indicates that there is no adequate exploration of these relationships and their contextual nature. As Bélanger and Crossler [15] and Smith, Dinev, and $\mathrm{Xu}$ [17] suggested, the issue of how various contexts may influence privacy and privacy-related proxies still needs to be fully investigated. Second, some firms view consumers' data collection as an opportunity to improve marketing returns [83]. However, we know very little about the ramifications of firms' customer data management, let alone consumers' behavioral responses that might follow. Any privacy-related misconduct by firms may give rise to consumers' negative responses, which ultimately exert adverse effects on firm performance [5]. Hence, the differentiated impact of privacy-related practices on consumers' behaviors and consumer behavioral variability from the perspective of information privacy could be considered important topics for future research. Third, recent literature has produced few insights regarding the issue of what coping strategy to adopt under what conditions. An important management issue for marketers and researchers is to determine the appropriate policies or regulations firms should adopt to mitigate the adverse effects of consumers' resistant behaviors due to unreasonable access to consumers' information. In addition, we may underestimate consumers' initiative to share their personal information due to the existence of consumers' privacy calculus. Most previous studies have not clearly discussed how to manage the delicate balance between privacy risks and benefits. Works by Zeithaml, Parasuraman, and Malhotra [84], Wolfinbarger and Gilly [85], Angst and Agarwal [86], and Youn [80] mention this issue.

\subsection{The Landscape from the Expanded Dataset}

To test the robustness of our identification of emerging trends in the landscape from a core dataset, the citation index-based expansion was used to re-construct a new dataset. Through expanding the core dataset, we can capture more information as much as possible. Table 6 presents 43 references that have the strongest citation bursts. Identical to the rules in the core dataset investigation, we review only those papers with the greatest link strength that start to burst in the same year. From 1999 to 2018, researchers focused on introducing the concept of consumer privacy and outline a taxonomy that explicitly describes specific privacy concerns for consumers [12]; combining existing literature and deployment requirements in a real-world environment of commercial user modeling servers for e-commerce to offer a requirement catalog [87]; investigating what makes a business-to-consumer (B2C) website effective [88]; investigating what drives online shoppers' intended use of an e-vendor [89]; exploring online service quality and providing theoretical and practical implications $[85,90]$; presenting a recent technical literature review to investigate a series of problems regarding the relevance between radio frequency identification (RFID) and privacy and security [91]. examining the inherent links among variables including website usability perception, trust, satisfaction, and loyalty [92]. conceptualizing a trust-based consumer decision-making model in which they explore how trust and perceived risk may operate in combination to affect electronic purchase decisions [93]; investigating the determining factors affecting consumer acceptance of e-shopping [94]; extending the privacy calculus model to examine the personalization-privacy paradox in location-aware marketing [95]. 
Table 6. Top 43 references with the strongest citation bursts.

\begin{tabular}{|c|c|c|c|c|}
\hline References & Str. & Begin & End & 1997-2019 \\
\hline Wang HQ.1998, Commun ACM & 3.41 & 1999 & 2002 & $=0$ \\
\hline Fink J. 2000, User Mod User-Adap & 11.22 & 2000 & 2005 & 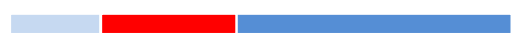 \\
\hline Culnan MJ. 1999, Organ Sci & 22.04 & 2002 & 2006 & 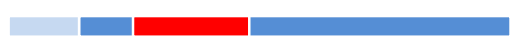 \\
\hline Hoffman DL. 1999, Commun ACM & 21.65 & 2002 & 2006 & m \\
\hline Ben Schafer J. 2001, Dat Min Know & 20.74 & 2002 & 2006 & n \\
\hline Ranganathan C. 2002, Info Manage & 25.33 & 2003 & 2007 & an \\
\hline Miyazaki AD. 2001, J Consum Aff & 24.05 & 2003 & 2007 & 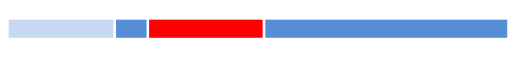 \\
\hline Ba SL. 2002, MIS Quart & 12.65 & 2003 & 2007 & $\mathbf{n}^{-1}$ \\
\hline Gefen D. 2003, MIS Quart & 32.13 & 2004 & 2008 & n \\
\hline Ben SJ. 2001, Data Min Know Disc & 29.52 & 2004 & 2009 & - \\
\hline Mcknight DH. 2001, Int J Electr C & 28.58 & 2004 & 2009 & -1 \\
\hline Pavlou PA. 2003, Int J Electro Com & 27.19 & 2004 & 2008 & nt \\
\hline Suh B. 2003, Int J Res Mark & 15.44 & 2004 & 2008 & 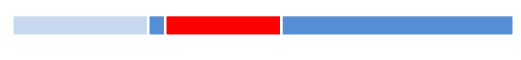 \\
\hline Shankar V. 2003, Int J Res Mark & 5.5 & 2004 & 2008 & + \\
\hline Wolfinbarger M. 2003, J Retailing & 17.92 & 2005 & 2011 & + \\
\hline Koufaris M. 2004, Info Manage & 16.88 & 2005 & 2009 & 10 \\
\hline Weis SA. 2004, Lect Note Compu Sc & 15.67 & 2005 & 2009 & $=1$ \\
\hline Rust RT. 2004, J Marketing & 6.62 & 2005 & 2010 & 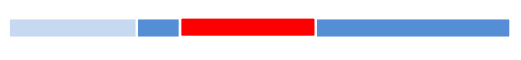 \\
\hline Parasuraman A. 2005, J Serv Res & 56.91 & 2006 & 2010 & 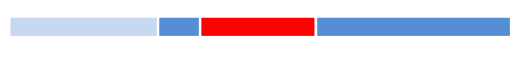 \\
\hline Pavlou PA. 2004, Info Syst Res & 31.78 & 2006 & 2010 & +2 \\
\hline Suh B. 2003, Intj Electr Comm & 28.82 & 2006 & 2010 & 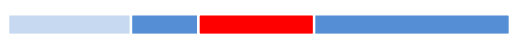 \\
\hline Schroeder SA. 2005, Jama-J Am Med & 22.17 & 2006 & 2010 & पn \\
\hline Malhotra NK. 2004, Info Syst Res & 16.65 & 2006 & 2011 & $+n$ \\
\hline Vijayasarathy LR. 2004, Info Man & 16.18 & 2006 & 2011 & 1 \\
\hline Juels A. 2006, J Sel Area Comm & 44.06 & 2007 & 2011 & 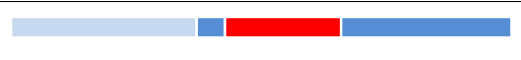 \\
\hline Schlosser AE. 2006, J Marketing & 14.7 & 2007 & 2011 & 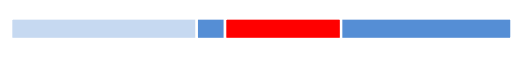 \\
\hline Flavian C. 2006, Ind Manag Dat Syst & 12.44 & 2007 & 2011 & 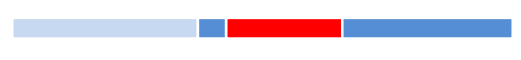 \\
\hline Flavian C. 2006, Info Manage & 36.75 & 2008 & 2012 & 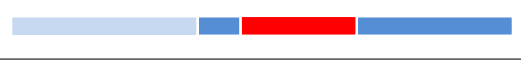 \\
\hline Safran C. 2007, J Am Med Info Assn & 22.43 & 2008 & 2012 & 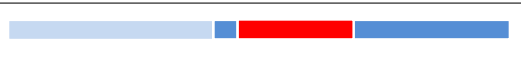 \\
\hline Loiacono ET. 2007, Int J Electro Com & 21.88 & 2008 & 2012 & 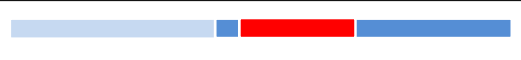 \\
\hline Cyr D. 2008, J Manage Info Syst & 20.79 & 2008 & 2013 & 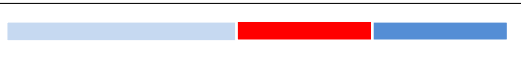 \\
\hline Chen YH. 2007, Ind Manage Dat Sys & 18.05 & 2008 & 2012 & ang \\
\hline Hwang YJ. 2007, Decis Supp Syst & 12.57 & 2008 & 2012 & (1) \\
\hline Kim DJ. 2008, Decis Support Syst & 51.79 & 2009 & 2013 & ald \\
\hline Hossain MM. 2008, IEE T En Manag & 7.9 & 2009 & 2013 & al \\
\hline
\end{tabular}


Table 6. Cont.

\begin{tabular}{cccc}
\hline References & Str. & Begin & End \\
\hline Ha S. 2009, J Bus Res & 32.12 & 2010 & 2014 \\
\hline Lee MC. 2009, Electr Commer R A & 27.6 & 2010 & 2014 \\
\hline Pavlou PA. 2007, MIS Quart & 20.56 & 2010 & 2014 \\
\hline Kim DJ. 2009, Info Syst Res & 17.55 & 2010 & 2016 \\
\hline Goldfarb A. 2011, Manage Sci & 13.22 & 2011 & 2015 \\
\hline Li YM. 2011, Comput Hum Behav & 10.91 & 2011 & 2018 \\
\hline Xu H. 2011, Decis Supp Syst & 15.81 & 2012 & 2018 \\
\hline Lin HF. 2011, Int J Info Manage & 14.31 & 2012 & 2014 \\
\hline
\end{tabular}

Some conclusions can thus be drawn. First, some articles with the strongest citation bursts, such as Culnan and Armstrong [13], Hoffman, Novak, and Peralta [82], Miyazaki and Krishnamurthy [75], Flavián and Guinalíu [92], Kim, Ferrin, and Rao [93], Goldfarb and Tucker [76], and Pavlou, Liang, and Xue [78] were identified again within a broader dataset scope, which underlines the importance of these influential studies. Second, it must be noted that some studies may exhibit emerging trends that have not yet been reflected within the landscape from the core dataset. For instance, there has been an apparent dearth of investigation on technical research in this domain. Despite the important contributions made by Ohkubo, Suzuki, and Kinoshita [96], Eckfeldt [97], and Juels [91], it is imperative to bridge the gaps between technical application and consumer privacy, which proves to be a great challenge. Third, some earlier basic research, such as Hoffman, Novak and Peralta [82], Jones [10], Wang, Lee, and Wang [12], Phelps, Nowak, and Ferrell [50], Miyazaki and Krishnamurthy [75], Culnan and Armstrong [13], and Pavlou [70] have contributed the most to this domain thus far. These research trends cohere with what we found in the landscape from the core dataset.

\section{Discussion and Conclusions}

In this paper, we used CiteSpace software and examined bibliographic records to provide state-of-the-art consumer privacy research as well as a glimpse of how this field may evolve in the future. To obtain a deep look into the whole picture of consumer privacy research, two datasets (core dataset and citation expanded dataset) were retrieved for analysis. Based on the analysis of the core dataset, we presented intellectual landscapes, including contributing journals, institutions, countries, and authors, as well as the evolution of research attention, emergent research clusters, and influential studies. Most importantly, emerging research trends were identified that may be useful for future research opportunities in the field of consumer privacy. We further investigated the expanded dataset to elucidate the emerging trends from a broader landscape. There are some notable findings with regard to the existing literature. First, the results show that consumer privacy has become an extremely valuable research area in the marketing field, as evidenced by advances in worldwide research output, theoretical development, and empirical investigation over the past decade. Second, the chronological distribution of keywords, network clusters, and the results of structural variation facilitated our understanding of the entire evolution of consumer privacy research. In other words, we identified not only previously popular topics but also some recent research trends. Taking recent topics as an example, studies have reflected the emergence of various research contexts (e.g., healthcare, financial, e-banking, and online payment). In addition, a transitional research trend was identified, such as Reagle J [63], Earp JB [64], Bansal G [65], Brandimarte L [66], Moores 
T [67], Tang Z [68], John LK [69], Pavlou PA [70], Norberg PA, [71] and Acquisti A [72]. Third, earlier influential works in the field were identified, including Hoffman, Novak and Peralta [82], Jones [10], Wang, Lee, and Wang [12], Phelps, Nowak, and Ferrell [50], Miyazaki and Krishnamurthy [75], Culnan and Armstrong [13], and Pavlou [70]. These studies are important in terms of not only how they connect previously disparate patches of knowledge in a synthesized network but also their ground-breaking contributions to drive transformative changes of the knowledge in the consumer privacy domain. Therefore, they should be given adequate attention in the near future.

Our study also reveals some emerging topics that remain a challenge for future research in the domain. First, topics on consumer behavior have obviously dominated privacy research in the past few years. More empirical studies are needed to shed further light on the privacy-related influence mechanism, especially in contemporary research contexts such as healthcare, digital payment, online purchase, and mobile application. In these contemporary contexts, future studies are recommended on how firms' personal data use affects consumers' attitude, cognition, perception, trust, and subsequent behaviors; how tailored measures are developed; how specific firms' data management practices affect customer behaviors, and how any new relationship dimensions can benefit from marketing theorists and practitioners. Analyzing the relationship between privacy and consumer behavior in different contexts enables marketers to effectively meet consumer expectations. Second, only a handful of studies highlight the impact of data privacy on organizations. It is necessary to conduct in-depth explorations of the effects of consumers privacy awareness on organizations' performance and practices. We believe that there are still some interesting research questions worthy of investigation regarding how specific consumer privacy concerns or awareness impact firms' performance and business strategies (e.g., marketing mix, product or service innovation) and how competitors will react in terms of marketing actions in personal data use. Third, though most of the articles we reviewed discuss consumers' willingness to trade their personal information for benefits, there is room for exploring what type of privacy content might be voluntarily traded by consumers for benefits, what the acceptance threshold is for consumers to agree to the implicit collection of information, particularly when it involves different contexts, and what this acceptance depends on. Fourth, as the public becomes aware of their rights to data privacy, consumers' trust and loyalty show more vulnerabilities once they recognize that their rights being violated [5]. Further studies could examine firm's recovery strategies to make amends or restore their customer relationships following events such as privacy leaks. Academicians and practitioners should give greater attention to appropriate marketing strategies that firms could take to mitigate the adverse effects of consumers' resistant behaviors. Fifth, firms might face ethical questions about the use of consumer data and analytics because less sophisticated consumers are more likely to be targeted by the sellers through quality or price discrimination. Therefore, it is imperative to promote social equity and protect public welfare via relevant laws and regulations. Further research might address what appropriate policies or regulations can be used to constrain firms' discrimination (e.g., pricing, racial, economic) against consumers due to the deployment of usage-enforcing technologies. Moreover, some thoughts must be considered with regard to how to synthesize organization, consumer, and ethical perspectives under an overall framework to understand privacy in marketing. Finally, these research trends call for the need to pinpoint the technical solution to privacy issues. As a double-edged sword, the advance of information technology has brought both positive and negative effects. Further researchers can design research on the relationship between legitimate technical applications and consumer privacy from a marketing perspective. For example, researchers need to know how the impact of privacy-enhancing technologies (e.g., RFID, user microtargeting technologies, sensor-based technologies) leads to consumer privacy concerns and behavior. Conversely, when firms deploy usage-enforcing technologies that ultimately jeopardize consumer welfare and benefits, more focus should be placed on 
what kinds of technological solutions can be leveraged to minimize or even avoid negative reactions to the use of personal data and benefit both firms and consumers.

From the results presented, we may also find some implications for practitioners in the marketing field. Privacy-related consideration is becoming one of the most important factors affecting consumer attitude, judgment, and behavior, which implies that firms' privacy practice is closely related to their ultimate performance. Although more convenient services such as personalized service offerings and recommendations can be provided by many firms using consumer data, firms that prioritize data privacy protection are bound to be more highly valued by consumer. Marketers, as decision makers implementing marketing strategies, need to be aware of such changes among consumers regarding privacy concerns and their impact on consumer decisions. More training should be carried out in order to adapt to the new business environment.

Undoubtedly, this study has certain limitations. First, although we attempted to perform an extensive literature search, it is likely that we did not capture all records for analysis due to the limitations of our database. The edition of the Web of Science (Core Collection) we searched only supports retrospective research from the year 1985 to the present. However, this limitation does not affect our analysis results because the theoretical study of consumer privacy did not begin until the 1990s [10]. Second, in this study, we focused on only information privacy from a marketing perspective. Future studies could concentrate on a wider range of search terms, because our study's limited keywords and search parameters might lead to missed items. Third, CiteSpace supports bibliographic and citation data retrieved from a variety of sources, such as Scopus, Google Scholar, and more. Thus, future research can extend the sample of research records by using these sources to reach more robust conclusions. Finally, authors' production analysis could be further analyzed. It would be interesting for future research to explore topics such as influential authors' publishing activity and their impact on this field, as well as authors' collaboration network in terms of a subset of topics.

Author Contributions: Conceptualization, Y.L.; Methodology, S.S.; Formal analysis, S.S.; Investigation, S.S.; Resources, Y.L.; Funding acquisition, Y.L.; Writing-original draft preparation, S.S.; Validation, Y.L. All authors have read and agreed to the published version of the manuscript.

Funding: This research was funded by the National Natural Science Foundation of China, grant number: 71832008.

Acknowledgments: The authors appreciate valuable suggestions from anonymous reviewers and Editor-in-Chief, which greatly improved the quality of the study.

Conflicts of Interest: The authors declare no conflict of interest.

\section{References}

1. Pavlou, P.A.; Fygenson, M. Understanding and predicting electronic commerce adoption: An extension of the theory of planned behavior. MIS Q. 2006, 30, 115-143. [CrossRef]

2. Rohunen, A.; Markkula, J.; Heikkilä, M.; Heikkilä, J. Open traffic data for future service innovation: Addressing the privacy challenges of driving data. J. Theor. Appl. Electron. Commer. Res. 2014, 9, 71-89. [CrossRef]

3. Anderson, C.; Baskerville, R.L.; Kaul, M. Information security control theory: Achieving a sustainable reconciliation between sharing and protecting the privacy of information. J. Manag. Inf. Syst. 2017, 34, 1082-1112. [CrossRef]

4. Hallam, C.; Zanella, G. Online self-disclosure: The privacy paradox explained as a temporally discounted balance between concerns and rewards. Comput. Hum. Behav. 2017, 68, 217-227. [CrossRef]

5. Martin, K.D.; Borah, A.; Palmatier, R.W. Data privacy: Effects on customer and firm performance. J. Mark. 2017, 81, 36-58. [CrossRef]

6. Meijer, R.; Conradie, P.; Choenni, S. Reconciling contradictions of open data regarding transparency, privacy, security and trust. J. Theor. Appl. Electron. Commer. Res. 2014, 9, 32-44. [CrossRef]

7. Okazaki, S.; Li, H.; Hirose, M. Consumer privacy concerns and preference for degree of regulatory control. J. Advert. 2009, 38, 63-77. [CrossRef]

8. Culnan, M.J.; Bies, R.J. Consumer privacy: Balancing economic and justice considerations. J. Social Issues. $2003,59,323-342$. [CrossRef]

9. Goodwin, C. Privacy: Recognition of a consumer right. J. Public Policy Mark. 1991, 10, 149-166. [CrossRef] 
10. Jones, M.G. Privacy: A significant marketing issue for the 1990s. J. Public Policy Mark. 1991, 10, 133-148. [CrossRef]

11. Smith, H.J.; Milberg, S.J.; Burke, S.J. Information privacy: Measuring individuals' concerns about organizational practices. MIS Q. 1996, 20, 167-196. [CrossRef]

12. Wang, H.; Lee, M.K.O.; Wang, C. Consumer privacy concerns about internet marketing. Commun. ACM 1998, 41, 63-70. [CrossRef]

13. Culnan, M.J.; Armstrong, P.K. Information privacy concerns, procedural fairness, and impersonal trust: An empirical investigation. Organ. Sci. 1999, 10, 104-115. [CrossRef]

14. Pavlou, P.A. State of the information privacy literature: Where are we now and where should we go? MIS Q. 2011, 35, 977-988. [CrossRef]

15. Bélanger, F.; Crossler, R.E. Privacy in the digital age: A review of information privacy research in information systems. MIS Q. 2011, 35, 1017-1042. [CrossRef]

16. Li, Y. Theories in online information privacy research: A critical review and an integrated framework. Decis. Support Syst. 2012, 54, 471-481. [CrossRef]

17. Smith, H.J.; Dinev, T.; Xu, H. Information privacy research: An interdisciplinary review. MIS Q. 2011, 35, 989-1016. [CrossRef]

18. Moxham, H.; Anderson, J. Peer review: A view from the inside. Sci. Technol. Policy 1992, 5, 7-15.

19. Van Raan, A. The use of bibliometric analysis in research performance assessment and monitoring of interdisciplinary scientific developments. TATuP-Zeitschrift für Technikfolgenabschätzung in Theorie und Praxis 2003, 12, 20-29. [CrossRef]

20. Preibusch, S. Guide to measuring privacy concern: Review of survey and observational instruments. Int. J. Hum. Comput. Stud. 2013, 71, 1133-1143. [CrossRef]

21. Gerber, N.; Gerber, P.; Volkamer, M. Explaining the privacy paradox: A systematic review of literature investigating privacy attitude and behavior. Comput. Secur. 2018, 77, 226-261. [CrossRef]

22. Yun, H.; Lee, G.; Kim, D.J. A chronological review of empirical research on personal information privacy concerns: An analysis of contexts and research constructs. Inf. Manag. 2019, 56, 570-601. [CrossRef]

23. Buckland, M.; Gey, F. The relationship between recall and precision. J. Am. Soc. Inf. Sci. 1994, 45, 12-19. [CrossRef]

24. Chen, C.; Hu, Z.; Liu, S.; Tseng, H. Emerging trends in regenerative medicine: A scientometric analysis in CiteSpace. Expert Opin. Biol. Ther. 2012, 12, 593-608. [CrossRef]

25. Serenko, A.; Bontis, N. Meta-review of knowledge management and intellectual capital literature: Citation impact and research productivity rankings. Knowl. Process Manag. 2004, 11, 185-198. [CrossRef]

26. Chen, C. Predictive effects of structural variation on citation counts. J. Am. Soc. Inf. Sci. Technol. 2012, 63, 431-449. [CrossRef]

27. Boyack, K.W.; Klavans, R. Co-citation analysis, bibliographic coupling, and direct citation: Which citation approach represents the research front most accurately? J. Assoc. Inf. Sci. Technol. 2010, 61, 2389-2404. [CrossRef]

28. Small, H. Co-citation in the scientific literature: A new measure of the relationship between two documents. J. Am. Soc. Inf. Sci. 1973, 24, 265-269. [CrossRef]

29. Small, H.; Greenlee, E. Citation context analysis of a co-citation cluster: Recombinant-DNA. Scientometrics 1980, 2, $277-301$. [CrossRef]

30. Samet, H. Applications of spatial data structures computers graphics, image proc. Scentometrics 1990, 2, $277-301$.

31. Chen, $\mathrm{C}$. The centrality of pivotal points in the evolution of scientific networks. In Proceedings of the 10th International Conference on Intelligent User Interfaces, San Diego, CA, USA, 10-13 January 2005; pp. 98-105.

32. Kleinberg, J. Bursty and hierarchical structure in streams. Data Min. Knowl. Discov. 2003, 7, 373-397. [CrossRef]

33. Chen, C.; Dubin, R.; Kim, M.C. Orphan drugs and rare diseases: A scientometric review (2000-2014). Expert Opin. Orphan Drugs 2014, 2, 709-724. [CrossRef]

34. Freeman, L.C. A set of measures of centrality based on betweenness. Sociometry 1977, 40, 35-41. [CrossRef]

35. Leydesdorff, L.; Rafols, I. A global map of science based on the isi subject categories. J. Am. Soc. Inf. Sci. Technol. 2009, 60, 348-362. [CrossRef]

36. Chen, C.; Ibekwe-Sanjuan, F.; Hou, J. The structure and dynamics of cocitation clusters: A multiple-perspective cocitation analysis. J. Assoc. Inf. Sci. Technol. 2010, 61, 1386-1409. [CrossRef]

37. Karimov, F.P.; Brengman, M.; Hove, L.V. The Effect of Website Design Dimensions on Initial Trust: A Synthesis of the Empirical Literature. J. Electron. Commer. Res. 2011, 12, 272.

38. Susanto, A.; Lee, H.; Zo, H.; Ciganek, A.P. User acceptance of Internet banking in Indonesia: Initial trust formation. Inf. Dev. 2013, 29, 309-322. [CrossRef]

39. Yang, H.; Lee, H.; Zo, H. User acceptance of smart home services: An extension of the theory of planned behavior. Ind. Manag. Data Syst. 2017, 117, 68-89. [CrossRef]

40. Rauschnabel, P.A.; He, J.; Ro, Y.K. Antecedents to the adoption of augmented reality smart glasses: A closer look at privacy risks. J. Bus. Res. 2018, 92, 374-384. [CrossRef]

41. Peppet, S.R. Regulating the internet of things: First steps toward managing discrimination, privacy, security and consent. Tex. $L$. Rev. 2014, 93, 85-179.

42. Calo, R. Digital market manipulation. Georg. Wash. Law Rev. 2013, 82, 995. [CrossRef]

43. Porat, A.; Strahilevitz, L.J. Personalizing default rules and disclosure with big data. Mich. L. Rev. 2013, 112, 1417. [CrossRef]

44. Birnhack, M.; Elkin-Koren, N. Does law matter online-empirical evidence on privacy law compliance. Mich. Telecomm. Tech. L. Rev. 2010, 17, 337. 
45. Martin, K.D.; Murphy, P.E. The role of data privacy in marketing. J. Acad. Mark. Sci. 2017, 45, 135-155. [CrossRef]

46. Eastlick, M.A.; Lotz, S.L.; Warrington, P. Understanding online B-to-C relationships: An integrated model of privacy concerns, trust, and commitment. J. Bus. Res. 2006, 59, 877-886. [CrossRef]

47. Li, T.; Unger, T. Willing to pay for quality personalization? Trade-off between quality and privacy. European. J. Inf. Syst. 2012, 21, 621-642. [CrossRef]

48. Liao, C.; Liu, C.C.; Chen, K. Examining the impact of privacy, trust and risk perceptions beyond monetary transactions: An integrated model. Electron. Commer. Res. Appl. 2011, 10, 702-715. [CrossRef]

49. Mohamed, N.; Ahmad, I.H. Information privacy concerns, antecedents and privacy measure use in social networking sites: Evidence from Malaysia. Comput. Hum. Behav. 2012, 28, 2366-2375. [CrossRef]

50. Phelps, J.; Nowak, G.; Ferrell, E. Privacy concerns and consumer willingness to provide personal information. J. Public Policy Mark. 2000, 19, 27-41. [CrossRef]

51. Wang, E.S.T. Role of privacy legislations and online business brand image in consumer perceptions of online privacy risk. J. Theor. Appl. Electron. Commer. Res. 2019, 14, 58-69. [CrossRef]

52. Zhou, T. The impact of privacy concern on user adoption of location-based services. Ind. Manag. Data Syst. 2011, 111, 212-226. [CrossRef]

53. Ancker, J.S.; Edwards, A.M.; Miller, M.C.; Kaushal, R. Consumer perceptions of electronic health information exchange. Am. J. Prev. Med. 2012, 43, 76-80. [CrossRef] [PubMed]

54. Vodicka, E.; Mejilla, R.; Leveille, S.G.; Ralston, J.D.; Elmore, J.G. Online access to doctors' notes: Patient concerns about privacy. J. Med. Internet Res. 2013, 15, 208. [CrossRef] [PubMed]

55. Zarcadoolas, C.; Vaughon, W.L.; Czaja, S.J.; Levy, J.; Rockoff, M.L. Consumers' perceptions of patient-accessible electronic medical records. J. Med. Internet Res. 2013, 15, 168. [CrossRef]

56. Mcknight, D.H.; Choudhury, V.; Kacmar, C. The impact of initial consumer trust on intentions to transact with a web site: A trust building model. J. Strateg. Inf. Syst. 2002, 11, 297-323. [CrossRef]

57. Mai, B.; Menon, N.M.; Sarkar, S. No free lunch: Price premium for privacy seal-bearing vendors. J. Manag. Inf. Syst. 2010, 27, 189-212. [CrossRef]

58. Gupta, B.; Iyer, L.S.; Weisskirch, R.S. Facilitating global e-commerce: A comparison of consumers' willingness to disclose personal information online in the U.S. and in India. J. Electron. Commer. Res. 2010, 11, 41-52.

59. Dinev, T.; Hart, P. An extended privacy calculus model for e-commerce transactions. Inf. Syst. Res. 2006, 17, 61-80. [CrossRef]

60. Xu, H.; Teo, H.H.; Tan, B.C.; Agarwal, R. The role of push-pull technology in privacy calculus: The case of location-based services. J. Manag. Inf. Syst. 2009, 26, 135-174. [CrossRef]

61. Xu, H.; Teo, H.H.; Tan, B.C.; Agarwal, R. Research note-Effects of individual self-protection, industry self-regulation, and government regulation on privacy concerns: A study of location-based services. Inf. Syst. Res. 2012, 23, 1342-1363. [CrossRef]

62. Dimitriadis, S.; Kyrezis, N. Linking trust to use intention for technology-enabled bank channels: The role of trusting intentions. Psychol. Mark. 2010, 27, 799-820. [CrossRef]

63. Reagle, J.; Cranor, L.F. The platform for privacy preferences. Commun. ACM 1999, 42, 48-55. [CrossRef]

64. Earp, J.B.; Anton, A.I.; Aiman-Smith, L.; Stufflebeam, W.H. Examining internet privacy policies within the context of user privacy values. IEEE Trans. Eng. Manag. 2005, 52, 227-237. [CrossRef]

65. Bansal, G.; Gefen, D. The impact of personal dispositions on information sensitivity, privacy concern and trust in disclosing health information online. Decis. Support. Syst. 2010, 49, 138-150. [CrossRef]

66. Brandimarte, L.; Acquisti, A.; Loewenstein, G. Misplaced confidences: Privacy and the control paradox. Soc. Psychol. Personal. Sci. 2013, 4, 340-347. [CrossRef]

67. Moores, T. Do consumers understand the role of privacy seals in e-commerce? Commun. ACM 2005, 48, 86-91. [CrossRef]

68. Tang, Z.; Hu, Y.; Smith, M.D. Gaining trust through online privacy protection: Self-regulation, mandatory standards, or caveat emptor. J. Manag. Inf. Syst. 2008, 24, 153-173. [CrossRef]

69. John, L.K.; Acquisti, A.; Loewenstein, G. Strangers on a plane: Context-dependent willingness to divulge sensitive information. J. Consum. Res. 2011, 37, 858-873. [CrossRef]

70. Pavlou, P.A. Consumer acceptance of electronic commerce: Integrating trust and risk with the technology acceptance model. Int. J. Electron. Commer. 2003, 7, 101-134.

71. Norberg, P.A.; Horne, D.R.; Horne, D.A. The privacy paradox: Personal information disclosure intentions versus behaviors. J. Consum. Aff. 2007, 41, 100-126. [CrossRef]

72. Acquisti, A.; John, L.K.; Loewenstein, G. What is privacy worth? J. Leg. Stud. 2013, 42, 249-274. [CrossRef]

73. Sheehan, K.B.; Hoy, M.G. Flaming, complaining, abstaining: How online users respond to privacy concerns. J. Advert. 1999, 28, 37-51. [CrossRef]

74. Pan, Y.; Zinkhan, G.M. Exploring the impact of online privacy disclosures on consumer trust. J. Retail. 2006, 82, 331-338. [CrossRef]

75. Miyazaki, A.D.; Krishnamurthy, S. Internet seals of approval: Effects on online privacy policies and consumer perceptions. J. Consum. Aff. 2002, 36, 28-49. [CrossRef]

76. Goldfarb, A.; Tucker, C.E. Privacy regulation and online advertising. Manag. Sci. 2011, 57. [CrossRef] 
77. Milne, G.R.; Rohm, A.J.; Bahl, S. Consumers' protection of online privacy and identity. J. Consum. Aff. 2010, 38, $217-232$. [CrossRef]

78. Pavlou, P.A.; Liang, H.; Xue, Y. Understanding and mitigating uncertainty in online exchange relationships: A principal-agent perspective. MIS Q. 2007, 31, 105-136. [CrossRef]

79. Tsai, J.Y.; Egelman, S.; Cranor, L.; Acquisti, A. The Effect of Online Privacy Information on Purchasing Behavior: An Experimental Study. Inf. Syst. Res. 2011, 22, 254-268. [CrossRef]

80. Youn, S. Determinants of online privacy concern and its influence on privacy protection behaviors among young adolescents. J. Consum. Aff. 2009, 43, 389-418. [CrossRef]

81. Tucker, C. Social networks, personalized advertising, and privacy controls. J. Mark. Res. 2014, 51, 546-562. [CrossRef]

82. Hoffman, D.L.; Novak, T.P.; Peralta, M. Building consumer trust online. Commun. ACM 1999, 42, 80-85. [CrossRef]

83. McAfee, A.; Brynjolfsson, E.; Davenport, T.H.; Patil, D.J.; Barton, D. Big data: The management revolution. Harv. Bus. Rev. 2012, 90, 60-68. [PubMed]

84. Zeithaml, V.A.; Parasuraman, A.; Malhotra, A. Service quality delivery through web sites: A critical review of extant knowledge. J. Acad. Mark. Sci. 2002, 30, 362-375. [CrossRef]

85. Wolfinbarger, M.; Gilly, M.C. eTailQ: Dimensionalizing, measuring and predicting etail quality. J. Retail. 2003, 79, 183-198. [CrossRef]

86. Angst, C.M.; Agarwal, R. Adoption of electronic health records in the presence of privacy concerns: The elaboration likelihood model and individual persuasion. MIS Q. 2009, 33, 339-370. [CrossRef]

87. Fink, J.; Kobsa, A. A review and analysis of commercial user modeling servers for personalization on the world wide web. User Modeling User-Adapt. Interact. 2000, 10, 209-249. [CrossRef]

88. Ranganathan, C.; Ganapathy, S. Key dimensions of business-to-consumer web sites. Inf. Manag. 2002, 39, 457-465. [CrossRef]

89. Gefen, D.; Karahanna, E.; Straub, D.W. Trust and TAM in online shopping: An integrated model. MIS Q. 2003, 27, 51-90. [CrossRef]

90. Parasuraman, A.; Zeithaml, V.A.; Malhotra, A. E-S-Qual: A multiple-item scale for assessing electronic service quality. J. Serv. Res. 2005, 7, 213-233. [CrossRef]

91. Juels, A. RFID security and privacy: A research survey. IEEE J. Sel. Areas Commun. 2006, 24, 381-394. [CrossRef]

92. Flavián, C.; Guinalíu, M.; Gurrea, R. The role played by perceived usability, satisfaction and consumer trust on website loyalty. Inf. Manag. 2006, 43, 1-14. [CrossRef]

93. Kim, D.J.; Ferrin, D.L.; Rao, H.R. A trust-based consumer decision-making model in electronic commerce: The role of trust, perceived risk, and their antecedents. Decis. Support. Syst. 2008, 44, 544-564. [CrossRef]

94. Ha, S.; Stoel, L. Consumer e-shopping acceptance: Antecedents in a technology acceptance model. J. Bus. Res. 2009, 62, 565-571. [CrossRef]

95. Xu, H.; Luo, X.; Carroll, J.M.; Rosson, M.B. The personalization privacy paradox: An exploratory study of decision-making process for location-aware marketing. Decis. Support. Syst. 2011, 51, 42-52. [CrossRef]

96. Ohkubo, M.; Suzuki, K.; Kinoshita, S. RFID privacy issues and technical challenges. Commun. ACM 2005, 48, 66-71. [CrossRef]

97. Eckfeldt, B. What does RFID do for the consumer? Commun. ACM 2005, 48, 77-79. [CrossRef] 